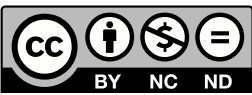

Estudos Teológicos foi licenciado com uma Licença Creative Commons Atribuição - NãoComercial - SemDerivados 3.0 Não Adaptada

http://dx.doi.org/10.22351/etv59i2.3761

\title{
NOVA ABORDAGEM PARA A CRÍTICA DA REDAÇÃO: A MEMÓRIA SOCIAL COMO REFERÊNCIA EM LUGAR DA DEPENDÊNCIA TEXTUAL ${ }^{1}$
}

New approach for the redaction criticism: social memory as reference in place of the textual dependence

\section{Marcelo da Silva Carneiro ${ }^{2}$}

Resumo: Por décadas, a Crítica da Redação, uma das ferramentas mais recentes entre os métodos histórico-críticos, fundamentou-se na dependência textual entre os evangelhos e suas fontes, especialmente a partir da Teoria das Duas Fontes. O objetivo deste artigo é mostrar uma nova perspectiva da Crítica da Redação a partir do conceito de memória social, que demonstra a importância da oralidade junto com a textualidade, tendo como fundamento a teoria de Maurice Halbwachs, e considerando como pesquisadores do Novo Testamento têm trabalhado com ela. A partir disso, o artigo faz uma comparação sinótica entre os evangelhos, contrapondo perspectivas tradicionais com a nova abordagem. Desse modo, procura-se demonstrar que as semelhanças e diferenças entre os evangelhos não são o trabalho isolado de um autor em sua perspectiva redacional, mas sobretudo a riqueza da memória da comunidade que gerou cada evangelho, imprimindo nele sua perspectiva sobre o evento Jesus.

Palavras-chave: Crítica da Redação. Memória social. Evangelhos. Tradição escrita. Tradição oral.

Abstract: For decades, the Redaction Criticism, one of the most recent tools among the Historical-Critical Methods, it was based on the textual dependence between the Gospels and their sources, especially since the emergence of Two-source Hypothesis. This article aims to show a new perspective of Redaction Criticism, from Social Memory Theory, which demonstrates the importance of Orality along with Textuality, from the Maurice Halbwachs' Theory, and how the New Testament researchers have worked with. Later the article will make a synoptic comparison between the Gospels, comparing the traditional perspective with the new approach. In this way, it seeks to demonstrate that the similarities and differences between the Gospels are not the

1 O artigo foi recebido em 30 de julho de 2019 e aprovado em 27 de agosto de 2019 com base nas avaliações dos pareceristas ad hoc.

2 Doutor. FATIPI-Faculdade de Teologia de São Paulo, São Paulo, SP. E-mail: professor.carneiro@hotmail. com 
isolated work of an author in his redactional perspective, but, especially, the wealth of Community memory that created each Gospel, printing on it their own perspective about the Jesus event.

Keywords: Redaction Criticism. Social memory. Gospels. Written tradition. Oral tradition.

\section{Introdução}

A Crítica da Redação (CR) é uma das abordagens histórico-críticas mais recentes e que aparentemente já não tem novidade para a exegese do Novo Testamento. Nascida na Alemanha, como resultado das pesquisas de Bornkamm e Conzelmann, com o nome de Redaktiongeschichte (História da Redação), conforme aponta Robert Stein em seu artigo de $1969^{3}$, a CR tem como parâmetro o estudo do texto final, buscando nele as características próprias de cada autor, em especial dos evangelhos.

Neste artigo, iremos analisar como a CR tem sido renovada em sua perspectiva desde que alguns autores começaram a relacionar a redação do texto com o uso de tradições orais baseados mais no conceito de memória social e menos no conceito de dependência textual a partir de um autor isolado. Para isso faremos uma análise em dois grandes momentos: no primeiro, dividido em quatro seções, refaremos os passos da origem até as novas perspectivas da CR. Começaremos pela necessária conceituação e história inicial da CR em suas origens e como ela foi recebida na pesquisa do NT. A seguir analisaremos as suas limitações, em especial a dependência textual que a CR demonstra nos seus pressupostos de como foi feito o processo redacional dos evangelhos, como se os textos tivessem sido criados somente a partir de fontes escritas. Para quebrar essa lógica falaremos sobre oralidade no mundo antigo, que era percebida de modo bastante diferente de nosso tempo, posto que apenas uma minoria daquela época tinha acesso à leitura e escrita. As consequências para a CR são mostradas a seguir por meio de pesquisas recentes que pensam a formação dos evangelhos com o conceito de memória social.

O segundo momento do artigo será, na quinta seção, uma pequena série de estudos de casos de textos sinóticos, em que analisaremos a forma como alguns manuais de exegese trabalharam a CR desses textos, e mostraremos a perspectiva da memória social aplicada a eles. Nesse ponto será necessário comparar textos - tanto dos evangelhos como dos autores de manuais - para que se possam perceber diferenças e semelhanças entre as abordagens, para então podermos concluir, analisando implicações e questões abertas sobre essa nova perspectiva.

3 STEIN, Robert H. What is Redaktionsgeschichte? Journal of Biblical Literature, v. 88, n. 1, p. 45-56, mar. 1969. 


\section{A Crítica da Redação: definição e limites}

Desde os anos de 1940, a pesquisa crítica sobre o Novo Testamento passou a enfatizar o papel do autor nos textos. ${ }^{4}$ Até então, as tendências na pesquisa evidenciavam as diferenças gerais entre os textos - na verdade, tal tendência começou mesmo na antiguidade e atravessou os séculos. ${ }^{5}$ Qual era a novidade então? Definir uma personalidade e um objetivo do redator sobre seu texto, imprimindo nele uma perspectiva própria. Em geral, as tendências estudavam os autores como compiladores das tradições orais e principalmente dos textos. Algumas obras mudaram essa perspectiva, dentre elas: Die Mitte der Zeit: Studien zur Theologie des Lukas, de Conzelmann (1954), Der Evangelist Markus, de Marxen (1956), Studien zum Matthäus-Evangelium (Wissenschaftliche Monographien zum Alten und Neuen), de Bornkamm, Barth e Held (1959). Todas elas estão voltadas ao estudo dos evangelhos e Atos dos Apóstolos. Na verdade, quando se fala em CR, costuma-se ter no horizonte mais os evangelhos do que outros textos do Novo Testamento. Ainda assim, Koester considera:

O método que três décadas mais tarde se tornou conhecido como "crítica da redação" não contribuiu com nada de novo; apenas apurou um pouco mais a análise dos materiais redacionais nos Evangelhos e resultou assim num reconhecimento mais detalhado das estratégias literárias dos redatores dos Evangelhos ${ }^{6}$.

Para entender melhor o que se busca analisar, vamos definir a CR. De acordo com os manuais de exegese ${ }^{7}$, essa abordagem pode ser entendida como o estudo do texto final, em que se buscam:

- a repetição de temas e motivos comuns dentro do mesmo evangelho;

- a comparação entre dois ou mais textos comuns, para indicar o mais antigo e como o posterior adicionou, omitiu ou alterou alguma coisa do texto anterior;

- o vocabulário e o estilo de um autor.

Ao levar em conta essas abordagens, alguns resultados foram consolidados com a Crítica da Redação: a primazia cronológica de Marcos sobre Mateus e Lucas; a antiguidade de Mateus em relação a Lucas; a possibilidade da existência de uma outra fonte escrita, diferente de Marcos, que forneceu diversos materiais para Mateus e Lu-

4 Cf. WEGNER, Uwe. Exegese do Novo Testamento: manual de metodologia. 7. ed. São Leopoldo: EST; Sinodal, 2012. p. 156.

5 Na modernidade, a pesquisa de J. J. Griesbach, que elaborou de forma metódica uma sinopse dos evangelhos, com o fim de clarificar as diferenças e semelhanças entre eles, é o ponto de partida. Daí surgiu a terminologia "Evangelhos Sinóticos" para Mateus, Marcos e Lucas, dadas as muitas aproximações temáticas e terminológicas entre eles. Cf. ORCHARD, Bernard; LONGSTAFF, Thomas R. W. (Ed.) J. J. Griesbach: Synoptic and text-critical studies. 1776-1976. Cambridge: Cambridge University Press, 1978.

6 KOESTER, Helmut. Introdução ao Novo Testamento 2. História e Literatura do Cristianismo Primitivo. São Paulo: Paulus, 2005. p. 65.

7 Cf. EGGER, Wilhelm. Metodologia do Novo Testamento. São Paulo: Loyola, 1994; SCHNELLE, Udo. Introdução à Exegese do Novo Testamento. São Paulo: Loyola, 2004; WEGNER, 2012. 
cas, denominada Fonte Q. Com esses resultados bem demonstrados, a pesquisa tendeu a aprofundar as análises, reforçando sempre certa dependência textual de um autor para outro. Isso resultou numa espécie de cristalização da teoria, em que a primazia de Marcos e a existência de Q tornaram-se praticamente indiscutíveis. Afinal, teria que haver uma fonte escrita, paralela a Marcos, que fosse utilizada por Mateus e Lucas. ${ }^{8}$

Não se podem esquecer duas abordagens que deram luz à $\mathrm{CR}$ e que mantêm uma estreita relação com ela: a Crítica Literária (CL) e a Crítica das Formas (CF), desenvolvidas entre os séculos XIX e XX. Da primeira a Crítica da Redação é devedora das teorias literárias que definiram a cronologia dos evangelhos, em especial a chamada Teoria das Duas Fontes, que abriu o espaço para discutir a Fonte Q, citada acima. Da segunda, podemos afirmar que a CR trabalha em paralelo com o conceito de Sitz im Leben (lugar vivencial), que estabelece em que espaço da vida comunitária os textos eram lidos, indicando assim seu objetivo básico. ${ }^{9}$

Entretanto, mesmo com toda a firmeza dessas teorias, diversas questões ficaram em aberto: o uso assimétrico de Marcos da parte de Mateus e Lucas, inclusive com boa quantidade de material marcano ficando fora dos demais evangelhos; a origem dos materiais exclusivos de Mateus e Lucas, especialmente os relatos da infância, etapa ignorada por Marcos; como realmente Mateus e Lucas usaram a fonte comum aos dois que não aparece em Marcos. ${ }^{10}$

\section{A Crítica da Redação e a dependência de fontes escritas}

O principal ponto em discussão que expõe a fraqueza da CR é o fato dela, a exemplo da CL e CF, depender muito da ideia de fontes escritas, dando pouca expressão a fontes orais. Na verdade, há quem afirme que a tradição oral só prevaleceu até o momento em que os evangelhos foram elaborados por escrito; a partir daí, prevaleceram a leitura e releitura dos textos. ${ }^{11}$

Podemos indicar aqui algumas obras onde a questão redacional acaba se resumindo a comparações entre textos escritos, onde termos como "omitir", "acrescentar", "alterar" e similares fazem parte do repertório técnico de comparação entre os textos.

Comecemos por Wegner ${ }^{12}$, que em seu manual utiliza as seguintes expressões para tratar das diferenças entre Mateus e Marcos: modificações nos verbos; acréscimos de expressões por parte de Mateus, quando Marcos não usa certa forma; omissões, como a menção aos escribas de Marcos 2.16; e a grande alteração redacional de Mateus, que cita de forma livre o profeta Oseias em Mateus 9.13. Mesmo não explicitando a dependência escrita, a abordagem de Wegner acaba dando a impressão de que

\footnotetext{
8 Cf. OPORTO, Santiago Guijarro. Ditos Primitivos de Jesus. Uma introdução ao "Proto-evangelho de ditos Q". São Paulo: Loyola, 2006.

9 Para aprofundar essas duas abordagens, ver WEGNER, 2012, p. 112-155; p. 203-278.

${ }^{10}$ KÜMMEL, Werner G. Introdução ao Novo Testamento. 2. ed. São Paulo: Paulus, 1982. p. 41-93.

${ }^{11}$ Cf. CARNEIRO, Marcelo. Os Evangelhos Sinóticos. Origens, memória e identidade. São Paulo: Fonte; Terceira Via, 2016. p. 54, 66.

12 Cf. WEGNER, 2012, p. 188ss.
} 
Mateus tinha o texto escrito de Marcos à sua frente e reelaborou o texto segundo sua proposta de escrever o evangelho.

Outro caso pode ser destacado da abordagem de Udo Schnelle, que em seu manual de exegese compara Mateus 21.33-46 com Msrcos 12.1-12. O foco dele está na forma como Mateus retrabalhou a perícope de Marcos. Após mostrar as diversas mudanças realizadas no texto, Schnelle conclui: "Em síntese, pode-se afirmar que Mateus adota o texto de Marcos nos aspectos essenciais, mas abrevia um pouco o curso da ação, conferindo-lhe ao mesmo tempo maior vivacidade e arredondando a linguagem"13. Com essa posição ele reforça essa dependência literária entre os evangelistas.

Um terceiro exemplo pode ser dado pelo estudo de Wilhelm Egger $^{14}$, que elaborou um quadro sobre a dependência textual existente entre os evangelhos. Egger parte da teoria da comunicação para explicar o fenômeno redacional. Nela, o processo se faz da seguinte forma: elaboração do texto (codificação); recepção do texto: coleção e seleção; elaboração do texto: sistematização, integração, reelaboração, criação de um conjunto unitário; (re)produção do texto. Egger ainda afirma:

\begin{abstract}
Não só para os evangelhos, mas para todos os textos neotestamentários (ainda que não na mesma medida) vale a afirmação de que o redator é compilador, escritor, teólogo e "evangelista": recolhe e seleciona o material necessário, o reelabora do ponto de vista estilístico e temático, cuida de organizá-lo e distribuí-lo; em determinados casos o integra com acréscimos mais ou menos extensos. Este trabalho complexo cria um novo texto, que é um conjunto unitário ${ }^{15}$.
\end{abstract}

O que esses três casos mostram é a perspectiva de uma relação direta entre textos escritos, que são revisados e reelaborados. Porém o que os autores desses manuais e os pesquisadores da CR iniciais não levaram em conta é o fator da oralidade não ser apenas um impulso inicial da transmissão da mensagem de e sobre Jesus, mas todo um processo dinâmico no mundo dentro do qual as comunidades cristãs estavam inseridas.

\title{
A oralidade no mundo Antigo
}

Para entender o cerne da questão precisamos rever o conceito de oralidade no qual viviam os povos da antiguidade: apesar de muita literatura ser produzida naquela época, apenas um percentual bem pequeno da população era letrado. Carneiro analisa o contexto de alfabetização e oralidade no Mediterrâneo antigo, e afirma que havia um

pequeno número de pessoas alfabetizadas, em geral, apenas homens, na Itália e no Mediterrâneo Ocidental. A alfabetização era, em pequena medida, um recurso das elites para ter acesso à arte escrita, como as novelas gregas. O maior propósito dela era evidentemente ser aplicada no governo do império, nas correspondências administrativas,

\footnotetext{
13 SCHNELLE, 2004, p. 139ss.

14 EGGER, 1994, p. 180ss.

15 EGGER, 1994, p. 180.
} 
e nas leis expostas em lugares públicos. [...] As pessoas analfabetas contratavam escribas tanto para escrever quanto para ler as correspondências. E no ambiente religioso os textos escritos registravam profecias e ordenanças divinas $[\ldots]^{16}$.

Ched Myers também aponta essa peculiaridade no mundo antigo, destacando que o judaísmo antigo tinha preferência pela recitação oral, tendo em vista as dificuldades técnicas e econômicas para a produção de material escrito. ${ }^{17} \mathrm{Ou}$ seja, podemos imaginar que em geral as leituras desses materiais eram públicas, e não particulares. Nesse mundo da oralidade pública, ouvir é um ato muito requerido e de forma alguma subestimado. A memória auditiva estava lado a lado com a memória factual e visual. É nesse contexto que os evangelhos foram redigidos, indicando que não se tornaram ponto de fixação da tradição, mas de transmissão fluida.

Ao falar de memória, nesse caso, tomamos como parâmetro o conceito de memória coletiva de Maurice Halbwachs, que aponta para a dinâmica da oralidade. Carneiro sintetiza a teoria da seguinte forma:

A abordagem de Halbwachs fundamenta o estudo da relação entre tradição oral, memória e o uso do passado. Seu estudo toma como ponto de partida o fato de que a memória é um fenômeno social, mesmo no âmbito individual. Todas as nossas memórias estão implicadas socialmente com as memórias do grupo com o qual convivemos ou do qual nos originamos. Ainda que uma pessoa se afaste de um grupo, há uma memória comum entre eles, que influencia decididamente na forma como o passado será lembrado ${ }^{18}$.

Esse conceito se encaixa de maneira bastante apropriada no mundo antigo, especialmente nas sociedade onde surgiram os evangelhos e demais textos do Novo Testamento. Mesmo os textos antigos sobre os evangelhos deixaram escapar uma percepção do uso da memória pelos evangelistas. Um bom exemplo é o de Justino Mártir. Em sua obra Primeira Apologia, ele apresenta os escritos evangélicos como memória dos apóstolos, que depois passaram a ser chamados de evangelhos. ${ }^{19} \mathrm{O}$ termo original apomnêmoneumata significa "lembrança", "aquilo que foi lembrado a partir de". Justino fez a associação dessa memória com os textos que foram produzidos para anunciar as boas coisas que Deus fez em favor das pessoas, aspecto que foi mais destacado na sua recepção. Curiosamente, para os pesquisadores dos séculos XIX e XX, a citação dos evangelhos como as lembranças a partir dos apóstolos não foi motivo de grande pesquisa, pois a importância da obra escrita era projetada para o mundo antigo com o mesmo valor que ela tinha nos séculos futuros. Porém, tendo em vista a realidade da oralidade e da textualidade naquele mundo dos cristãos primitivos, é necessário ter outra perspectiva para a elaboração dos textos.

${ }^{16}$ CARNEIRO, 2016, p. 74.

${ }^{17}$ Cf. MYERS, Ched. O Evangelho de São Marcos. São Paulo: Paulinas, 1992. p. 126.

${ }^{18}$ CARNEIRO, 2016, p. 37.

19 The First Apology, Cap. LXVII. In: ROBERTS, Alexander; DONALDSON, James (Ed.). Ante-Nicene Fathers. Buffalo: Public Domain, 1885. v. I, p. 185. 
Recentemente, a associação entre memória e experiência religiosa foi ressaltada por Guy Stroumsa. ${ }^{20}$ Em seu artigo, ele aborda a memória religiosa que atua de duas formas, paralelamente, na reconstrução de eventos, doutrinas e ideias: a memória semântica e a episódica. ${ }^{21}$ A memória semântica elabora a doutrina e as ideias, enquanto a episódica reforça a imagética e ritualística. Por exemplo, no tema da crucificação: enquanto os relatos dos evangelhos são fundados na memória episódica, que apresenta um quadro vívido da crucificação (cf., p. ex., Lucas 23.33-43), a abordagem de Paulo se sustenta na memória semântica sobre a cruz, explicando seu sentido e centralidade para a fé (cf. 1 Coríntios 1.18-25). Em todos os casos, se faz teologia, mas tendo como fundamento tipos diferentes de memória.

Essas memórias, sejam elas semânticas ou episódicas, são construídas na oralidade, mais que na textualidade. Eis aí o ponto central a ser pensado para a elaboração dos evangelhos. Partindo da ideia de que a oralidade era bastante difundida e que a textualidade não era considerada superior de fato (como ocorre em nossa sociedade), deve-se ter em conta que o registro por escrito dos evangelhos não determinou o fim da dinâmica da memória social das comunidades cristãs, ou seja, que a tradição oral não foi de fato interrompida. ${ }^{22}$

\section{A Crítica da Redação a partir da memória social}

O conceito de memória social pode ser um recurso importante para compreender a formação dos evangelhos. Um dos autores que tem trabalhado com afinco nessa perspectiva é Samuel Byrskog. Dois trabalhos dele mostram essa preocupação: um livro de 2002, Story as History - History as Story. The Gospel Tradition in the Context of Ancient Oral History, e um artigo mais recente, de 2006, publicado na revista New Testament Studies, "A New Quest for the Sitz im Leben: Social Memory, the Jesus Tradition and the Gospel of Matthew". Para nossos objetivos, iremos focar nesse segundo trabalho.

Nesse artigo, Byrskog relaciona a tradição com o Sitz im Leben numa perspectiva da $\mathrm{CR}$ e não da $\mathrm{CF}$, mesmo levando em consideração o espaço de memória da comunidade. Para ele, o Sitz im Leben tem o sentido de uma coleção de memórias usadas no presente, dentro de um contexto específico, que faz referência ao passado. Nesse processo, há uma integração de formas orais e escritas, sempre dentro do campo comunitário da memória. Essa integração fortalece a coexistência do grupo, pois estabelece os momentos mnemônicos - sejam eles rituais ou confessionais. Assim, se retroalimentam as memórias e crenças (como no caso do batismo e da eucaristia). Essa memória, por sua vez, está condicionada socialmente, e é onde ocorre o Sitz im Leben. O resultado é o fortalecimento dos laços do grupo a partir de um senso de iden-

${ }^{20}$ STROUMSA, Guy G. Religious Memory, between orality and writing. Memory Studies, v. 9, n. 3, p. 332-340, 2016.

${ }^{21}$ STROUMSA, 2016, p. 332.

${ }_{22}$ Cf. CARNEIRO, 2016, p. 77 ss. 
tidade gerado pelas memórias comuns. Byrskog entende, então, que o Sitz im Leben é uma ocasião recorrente na comunidade em que algumas pessoas reforçam a memória sobre Jesus e a utilizam de forma oral ou escrita, em que os evangelhos se tornam expressão documental do processo. ${ }^{23}$

Ao pensar no Evangelho de Mateus, que é o foco de Byrskog, ele relaciona diversos trechos em que Marcos aparece de forma desordenada e fragmentada em Mateus. Para os que pensam numa dependência literária escrita, torna-se um desafio sem fim estabelecer a lógica pela qual Mateus trabalha Marcos. Byrskog, no entanto, pensa de outro modo: no mundo da oralidade dos cristãos do século primeiro, Marcos é resultado de performances orais contínuas de episódios envolvendo Jesus. Mateus, por sua vez, revisou suas próprias memórias a partir das performances relacionadas com Marcos, seja pela leitura ou pela recitação oral. As reorientações do texto de Marcos em Mateus indicam uma liberdade criativa a partir de suas próprias atividades mnemônicas e uma reoralização da narrativa escrita de evangelho mais antigo. Ou seja, Mateus não estava fixado no texto escrito, mas trabalhava com ele ao mesmo tempo em que trabalhava com outras memórias da comunidade. ${ }^{24}$

A abordagem de Byrskog aproxima-se da de Kirk e Thatcher ${ }^{25}$, cuja pesquisa indicou que a memória não apenas reconstitui o passado, mas serve para reconstruí-lo a partir de novas vivências, reforçando a forma como a comunidade se compreende. Assim, construção da identidade está em direta relação com a reconstrução do passado. Para eles, a ausência da memória como categoria analítica nos evangelhos pode ser atribuída a diversos fatores, mas principalmente aos efeitos da CF, posto que essa tende a se fixar apenas no texto escrito, que passa a ser definido como a tradição recebida, de forma cristalizada. De acordo com eles, deve-se pensar que as comunidades estavam num processo dinâmico de compreensão do passado por meio da celebração, em contínua negociação com as vivências presentes. Tradição e memória estão, desse modo, em constante relação de mútua dependência, e não podem ser separadas.

Tanto Byrskog como Kirk e Thatcher indicam um aspecto importante nessa abordagem: a ideia de que a memória é construída coletivamente, não só resgatada de forma neutra e direta. Isso significa que, ao recordar, as comunidades estavam também elaborando como essas memórias faziam sentido para elas, tornando-se parte de sua própria história e identidade. No caso dos evangelhos, eles acabam sendo testemunhas desses caminhos criativos da memória social das comunidades, posto que os textos não são meras repetições uns dos outros, mas reelaborações, em que elementos podem ser inseridos ou estar ausentes, dependendo de como uma determinada história é recordada pela comunidade. É isso que veremos a seguir.

${ }^{23}$ BYRSKOG, 2006, p. 324ss.

${ }^{24}$ BYRSKOG, 2006, p. 328ss.

${ }^{25}$ KIRK, Alan; THATCHER, Tom (Ed.). Memory, Tradition, and Text. Use of the Past in Early Christianity. Atlanta: Society of Biblical Literature, 2005. 


\section{Estudos de caso}

Como procedimento, utilizaremos algumas terminologias e pressupostos:

Pressupostos: concordamos que a elaboração escrita dos evangelhos se deu a partir da década de 60 do século primeiro, começando por Marcos, sendo que Mateus e Lucas foram escritos após o ano 70, provavelmente 75-80 e 85-90, respectivamente. ${ }^{26}$ A relação entre eles é que será definida de uma maneira mais fluida que a posição tradicional, tendo em vista a dinâmica oral e textual da memória do grupo. Manteremos a nomenclatura nominal dos autores (Mt, Mc e Lc) por questões de clareza e objetividade, considerando que são títulos consagrados para essas obras.

Metodologicamente, utilizaremos a seguinte terminologia: reoralização, quando um texto for apropriado e relido a partir da performatização de um anterior ou paralelo; recurso mnemônico, no caso de estruturas similares nos textos que apontam para oralidade; inserção, omissão ou diferenciação, considerando as diferenças entre os textos, mesmo não havendo atividade redacional textual direta.

\section{Mc 2.15-17 comparado com Mt 9.10-13 e Lc 5.29-32 (Wegner)}

\begin{tabular}{|c|c|}
\hline $\begin{array}{l}\text { Mt 9.10-13: } \\
\text { 10: } \mathbf{E} \text { aconteceu que estava ele reclinado } \\
\grave{a} \text { mesa na casa e eis que muitos } \\
\text { coletores de impostos e pecadores, } \\
\text { tendo chegado, reclinaram à mesa } \\
\text { com Jesus e seus discípulos. }\end{array}$ & $\begin{array}{l}\text { Mc 2.15-17: } \\
\text { 15: E acontece estar ele reclinado à } \\
\text { mesa na casa [dele], e muitos coletores } \\
\text { de impostos e pecadores estavam } \\
\text { reclinados à mesa com Jesus e os } \\
\text { seus discípulos; [pois eram muitos e } \\
\text { seguiam-no]. }\end{array}$ \\
\hline $\begin{array}{l}\text { 11: E, tendo visto os fariseus, diziam } \\
\text { aos discípulos dele: Por que com os } \\
\text { coletores de impostos e pecadores } \\
\text { come o vosso mestre? }\end{array}$ & $\begin{array}{l}\text { 16: } \mathbf{E} \text { os [escribas dos] fariseus, tendo } \\
\text { visto [que come com os pecadores e } \\
\text { coletores de impostos], diziam aos } \\
\text { discípulos dele: Por que com os coletores } \\
\text { de impostos e pecadores come? }\end{array}$ \\
\hline $\begin{array}{l}\text { 12: Ele, porém, tendo ouvido, disse: } \\
\text { Não têm necessidade de médico os que } \\
\text { são fortes, mas os que estão doentes. }\end{array}$ & $\begin{array}{l}\text { 17: E, tendo ouvido, o Jesus diz [a } \\
\text { eles]: Não têm necessidade de médico } \\
\text { os que são fortes, mas os que estão } \\
\text { doentes. }\end{array}$ \\
\hline $\begin{array}{l}\text { 13: Ide, porém, e aprendei o que } \\
\text { significa: misericórdia quero, e não } \\
\text { sacrifício. Pois não vim para chamar } \\
\text { justos, mas pecadores. }\end{array}$ & $\begin{array}{l}\text { Não vim para chamar justos, mas } \\
\text { pecadores }\end{array}$ \\
\hline
\end{tabular}

${ }^{26}$ Cf. CARNEIRO, 2016, p. 61-66, em que é apresentado o contexto histórico dentro do qual nasceram os evangelhos. Quanto às datações, os manuais de Wegner (p. 138-142) e Schnelle (p. 133) trabalham nessa mesma cronologia. 
Wegner ${ }^{27}$ propõe a seguinte legenda ao quadro comparativo:

negrito: coincidências literais entre os dois evangelhos;

itálico: uso de sinônimos ou modificações em tempos verbais, sem alteração de sentido;

sublinhado: acréscimos do mais recente em relação ao mais antigo (no caso Mt em relação a Mc);

[ ] Colchetes: omissões do mais recente em relação ao mais antigo (Mt em relação a Mc).

Em Mateus 9.10/Marcos 2.15, podemos destacar que a diferença de estilo pode se referir ao modo próprio de cada grupo contar suas histórias. Enquanto o grupo de Mateus utiliza o aoristo ("aconteceu"), o grupo de Marcos trabalha com o "presente histórico" ("acontece"), que nas traduções em português normalmente são transformadas em pretérito perfeito, tanto num caso quanto no outro, perdendo essa nuança. Em suma, trata-se de uma liberdade na forma de contar a história que circula entre as comunidades.

Para Wegner, no entanto, as modificações são "tentativas de melhorar o estilo, não alterando em nada o sentido da fonte usada" 28 . Na abordagem dele, as diferenças são realizadas num processo de redação em que Mateus leu Marcos e revisou o texto segundo seu objetivo. Para ele, por fim, ao omitir a expressão "escribas dos" no v. 11, "Mateus quis destacar um único grupo de opositores de cada vez, para melhor mostrar como a ruptura entre Jesus e os seus adversários atingia os principais representantes do judaísmo" 29 . A conclusão sobre o objetivo de Mateus é interessante e pode ser aplicada também na perspectiva da memória social, mas limita sua aplicação.

As coincidências entre os textos mostram que a forma como a narrativa foi transmitida tinha diversos elementos mnemônicos que eram repetidos de maneira sistemática e, por isso, reproduzidos fielmente. É o caso da expressão "muitos coletores de impostos e pecadores", repetida na pergunta dos fariseus. Outra repetição importante é a afirmação de conclusão de Jesus. Na perspectiva da CF, essa narrativa é um paradigma, um relato de controvérsia em que o ponto mais importante da história é o desfecho, com uma afirmação de Jesus que deve ser considerada paradigmática para a comunidade, daí a origem do termo que dá nome à forma da história. ${ }^{30}$ No caso dessa narrativa, a afirmação final de Jesus é o centro da narrativa, e a parte onde Mateus e Marcos são idênticos.

Entretanto, nesse trecho, Mateus faz uma inserção de Oseias 6.6, mostrando a gravidade da questão, e como Jesus está fundado na expressão profética da vontade divina. Esse recurso mateano vai se repetir em várias outras ocasiões (em especial no

\footnotetext{
${ }^{27}$ Cf. WEGNER, 2012, p. 189.

${ }^{28}$ WEGNER, 2012, p. 189.

${ }^{29}$ WEGNER, 2012, p. 190.

${ }^{30}$ Cf. WEGNER, 2012, p. 225ss.
} 
relato sobre o sábado, Mateus 12.1-7), e indica essa liberdade de inserir referências ao "AT" pelos organizadores do evangelho.

Na comparação entre Marcos e Lucas, podemos ver processos similares:

\begin{tabular}{|c|c|}
\hline $\begin{array}{l}\text { Lc 5.29-32: } \\
\text { 29: E Levi fez um grande banquete para } \\
\text { ele na casa dele, e estava uma grande } \\
\text { multidão de coletores de impostos e de } \\
\text { outros reclinados com ele à mesa. }\end{array}$ & $\begin{array}{l}\text { Mc 2.15-17: } \\
\text { 15: [E acontece estar ele reclinado à } \\
\text { mesa] na casa dele, e muitos coletores de } \\
\text { impostos [e pecadores] estavam reclinados } \\
\text { à mesa com Jesus [e os seus discípulos; } \\
\text { pois eram muitos e seguiam-no]. }\end{array}$ \\
\hline $\begin{array}{l}\text { 30: E murmuravam os fariseus e os } \\
\text { escribas deles para os discipulos dele, } \\
\text { dizendo: Por que com os coletores de } \\
\text { impostos e pecadores comeis e bebeis? }\end{array}$ & $\begin{array}{l}\text { 16: Eos escribas dos fariseus, [tendo visto } \\
\text { que come com os pecadores e coletores } \\
\text { de impostos, ] diziam aos discípulos dele: } \\
\text { Por que com os coletores de impostos e } \\
\text { pecadores come? }\end{array}$ \\
\hline $\begin{array}{l}\text { 31: E respondendo Jesus, disse a eles: } \\
\text { Não têm necessidade de médico os } \\
\text { sadios, mas os que estão doentes. }\end{array}$ & $\begin{array}{l}\text { 17: E, tendo ouvido, o Jesus diz a eles: } \\
\text { Não têm necessidade de médico os que } \\
\text { são fortes, mas os que estão doentes. }\end{array}$ \\
\hline $\begin{array}{l}\text { 32: Não vim chamar justos mas } \\
\text { pecadores para arrependimento. }\end{array}$ & $\begin{array}{l}\text { Não vim para chamar justos, mas } \\
\text { pecadores. }\end{array}$ \\
\hline
\end{tabular}

O comentário de Wegner ${ }^{31}$ na comparação de Marcos e Lucas aponta dois aspectos fundamentais, com os quais concordamos:

(1) Lucas altera a forma como a pergunta é feita pelos fariseus. Em vez deles questionarem o fato de Jesus comer com os pecadores, eles questionam por que os discípulos comem e bebem (acréscimo lucano) com os pecadores. Aparentemente pequeno, isso mostra uma atualização do problema da comensalidade. Considerando que Lucas/Atos são textos que estão na fronteira do mundo gentílico e judaico ${ }^{32}$, a comensalidade entre esses dois grupos é uma realidade de desafio e questionamento, lembrando as discussões de Atos 15; Gálatas 2.11-14; Romanos 14.1ss, entre outros.

(2) O acréscimo da expressão "para arrependimento" no fim tem um forte valor teológico para Lucas, que nisso também se difere de Mateus e Marcos. Enquanto esses só utilizam esse termo relacionado a João Batista, na obra lucana essa terminologia é utilizada também na pregação de Jesus, como se pode ver na comparação entre Mateus 18.13 e Lucas 15.7:

\footnotetext{
31 WEGNER, 2012, p. 193s.

32 Cf. CARNEIRO, 2016, p. 275ss.
} 


\section{Mt 18.13:}

E, se porventura a encontra, em verdade vos digo que maior prazer sentirá por causa desta do que pelas noventa e nove que não extraviaram.

\section{Lc 15.7:}

Digo-vos que, assim, haverá maior júbilo no céu por um pecador que se arrepende do que por noventa e nove justos que não necessitam de arrependimento.

Isso indica uma ênfase teológica em Lucas que não está presente nos demais sinóticos, motivada pelo contexto diferente no qual a comunidade está inserida. Mas que não está necessariamente atrelada a um esquema redacional especificamente escrito, pelo contrário, podem ser adendos produzidos na própria performatização oral desses textos.

Como conclusão dessas análises, percebe-se que no todo as histórias são repetidas de forma igual, havendo diferenças em detalhes que não alteram a natureza das histórias, porém demonstram a liberdade com a qual as comunidades lidavam com a tradição recebida. Fica marcada, de fato, a força da memória em torno de histórias marcantes sobre Jesus e os discípulos. No Sitz im Leben dos textos, percebe-se a prédica ou a catequese de novos membros, para reforçar comportamentos positivos na comunidade.

\section{Mt 21.33-46 comparado com Mc 12.1-12 (Schnelle)}

Mt 21.33-46:
33: Outra parábola ouvi: Havia um
homem, senhor da casa, que plantou
uma vinha e pôs uma cerca ao redor
dela e cavou nela um lagar e construiu
uma torre e arrendou-a a lavradores
e foi viajar.

34: E quando se aproximou o tempo dos frutos, enviou os servos dele até os lavradores para receber seus frutos.

35: E os lavradores, tomando os servos dele, a um espancaram, a outro mataram, a outro apedrejaram.

36: Enviou novamente outros servos em maior número que os primeiros, mas fizeram o mesmo com eles.
Mc 12.1-12:

1: [E começou a falar com eles por parábolas]: Um homem plantou uma vinha e pôr ao redor uma cerca e cavou um lagar e construiu uma torre e arrendou-a a lavradores e foi viajar.

2: E enviou no tempo certo um servo até os lavradores para que, junto aos lavradores, recebesse os frutos da vinha; 3: E tomando a ele, o espancaram e [enviaram embora vazio].

4: $E$ novamente enviou até eles outro servo; e àquele bateram na cabeça e insultaram.

5: E outro enviou; e àquele mataram, e muitos outros, a uns espancando, a outros matando. 


\begin{tabular}{|c|c|}
\hline $\begin{array}{l}\text { 37: E por fim enviou o seu filho até eles, } \\
\text { dizendo: Respeitarão o meu filho. }\end{array}$ & $\begin{array}{l}\text { 6: Ainda tinha um: o filho [amado]; } \\
\text { enviou-o [por último] até eles, dizendo: } \\
\text { Respeitarão o meu filho. }\end{array}$ \\
\hline $\begin{array}{l}\text { 38: Mas os lavradores, vendo o filho, dis- } \\
\text { seram entre eles: Este é o herdeiro; vin- } \\
\text { de, matemo-lo e peguemos sua herança. }\end{array}$ & $\begin{array}{l}\text { 7: Mas [aqueles] lavradores disseram } \\
\text { entre si: Este é o herdeiro; vinde, } \\
\text { matemo-lo e a herança será nossa. }\end{array}$ \\
\hline $\begin{array}{l}\text { 39: E tomando-o, lançaram fora da } \\
\text { vinha e mataram. }\end{array}$ & $\begin{array}{l}\text { 8: E tomando o mataram e lançaram } \\
\text { fora da vinha. }\end{array}$ \\
\hline $\begin{array}{l}\text { 40: Quando pois vier o senhor da vinha, } \\
\text { que fará àqueles lavradores? }\end{array}$ & \multirow{2}{*}{$\begin{array}{l}\text { 9: Que fará, pois, o senhor da vinha? } \\
\text { [Virá e] destruirá os lavradores e dará } \\
\text { a vinha a outros. }\end{array}$} \\
\hline $\begin{array}{l}\text { 41: Dizem a ele: Destruirá aos malvados } \\
\text { horrivelmente e arrendará a vinha a } \\
\text { outros lavradores, os quais entregarão a } \\
\text { ele os frutos nos seus devidos tempos. }\end{array}$ & \\
\hline \multirow{2}{*}{$\begin{array}{l}\text { 42: Jesus diz a eles: Nunca lestes nas } \\
\text { Escrituras: Pedra que os construtores } \\
\text { rejeitaram, esta veio a ser a pedra angular; } \\
\text { isto aconteceu da parte do Senhor, e é } \\
\text { maravilhoso aos nossos olhos? }\end{array}$} & $\begin{array}{l}\text { 10: Esta Escritura não lestes: Pedra que } \\
\text { os construtores rejeitaram, esta veio a } \\
\text { ser pedra angular; }\end{array}$ \\
\hline & $\begin{array}{l}\text { 11: isto aconteceu da parte do Senhor, e } \\
\text { é maravilhoso aos nossos olhos? }\end{array}$ \\
\hline \multicolumn{2}{|l|}{$\begin{array}{l}\text { 43: Por isso vos digo que o reino de } \\
\text { Deus será tirado de vós e será dado a } \\
\underline{\text { uma nação que produz seus frutos. }}\end{array}$} \\
\hline \multicolumn{2}{|l|}{$\begin{array}{l}\text { 44: E o que cai sobre esta pedra será } \\
\text { despedaçado; e sobre quem ela cair } \\
\text { reduzirá a pó. }\end{array}$} \\
\hline \multicolumn{2}{|l|}{$\begin{array}{l}\text { 45: E tendo ouvido os principais } \\
\text { sacerdotes e os fariseus as parábolas } \\
\text { dele_entenderam que a respeito dele está } \\
\text { falando; }\end{array}$} \\
\hline $\begin{array}{l}\text { 46: e procurando prendê-lo, temeram } \\
\text { as multidões, porque elas o tinham } \\
\text { como profeta. }\end{array}$ & $\begin{array}{l}\text { 12: E procuravam prendê-lo, [mas] } \\
\text { temeram a multidão, pois souberam } \\
\text { que falou a parábola contra eles. E } \\
\text { deixando-o, partiram. }\end{array}$ \\
\hline
\end{tabular}

Em sua análise, Schnelle ${ }^{33}$ aponta algumas diferenças marcantes entre os dois textos:

(1) Mateus faz questão de expressar que o homem era o oikodespotes (senhor ou dono da casa), fazendo aqui uma alusão a Deus mais forte do que em Marcos;

${ }^{33}$ SCHNELLE, 2004, p. 139ss. 
(2) o fato de o Senhor enviar vários servos em Mateus, diferentemente de Marcos, em que começa com um servo só, tira do texto o caráter de uso do cotidiano e aponta mais claramente para os profetas, que tanto pregaram contra os sacerdotes e príncipes;

(3) apesar de omitir o termo "amado" e não enfatizar a palavra escatos (último) do v. 6 de Marcos, Mateus reelabora a forma como o filho é morto, para aproximar ainda mais da tradição da Paixão: ele é morto fora da vinha (Jerusalém);

(4) como ocorre em outros casos, Mateus faz uma inserção de citações misturadas com informações novas nos v. 43 a 45, inclusive fazendo uma citação a Daniel $2.34 \mathrm{~s} .44 \mathrm{~s}$. Com essa inserção ele reforça a condenação daqueles que matariam Jesus;

(5) por fim, vale ressaltar que, enquanto em Marcos o próprio Jesus responde à pergunta crucial sobre o que aconteceria aos lavradores maus, Mateus cria um diálogo, colocando na boca dos adversários a própria condenação pelo fato de matarem o filho.

Algumas observações nossas, tendo em mente o critério da memória social:

(1) essa narrativa é mais longa e elaborada, havendo mais elementos para serem repassados. Por isso percebe-se bem menos coincidência entre os textos;

(2) o início é quase idêntico, o que mostra que havia uma força mnemônica na introdução da história, que depois se dispersa nas liberdades da forma de contar a narrativa;

(3) o trecho central do envio do filho, com algumas pequenas diferenças, também é reproduzido igualmente, indicando que era um ponto importante na memória da narrativa;

(4) o mesmo acontece com a citação do Salmo 118.22-23, que é reproduzida fielmente da versão da Septuaginta, ainda que possa ser tradução do hebraico;

(5) de forma mais dispersa, algumas palavras e pequenas expressões parecem ser chaves mnemônicas importantes na narrativa: "enviou novamente", "que fará o senhor?", "destruirá", "procuravam/procurando prendê-lo, temeram as multidões".

(6) os acréscimos de Mateus reforçam a gravidade da sentença contra as autoridades, mostrando como essa memória devia ser usada na comunidade para condenar aqueles que fracassaram na revolta contra Roma e ainda queriam liderar o judaísmo na Palestina.

Conclusão: nesse caso as diversas diferenças estilísticas, que não mudam o sentido geral, podem ser explicadas de forma ainda mais marcante como resultado das variações produzidas pela oralidade numa história maior. Porém, em determinados momentos cruciais, as narrativas reproduzem o mesmo teor, por isso a memória em torno da tradição recebida é mais firme e precisa. Por trás do texto está o Sitz im Leben de controvérsia com pessoas de fora da comunidade a respeito da messianidade de Jesus.

\section{Considerações finais}

Depois de todos esses aspectos apresentados, fica a pergunta: que diferença realmente faz analisar a CR sob a perspectiva da memória social? E, havendo diferenças, que implicações isso tem para o estudo do Novo Testamento, em especial dos evangelhos? 
Quanto à primeira pergunta, temos as seguintes considerações: conforme pode ser observado, concordamos com boa parte das afirmações dos exegetas de manuais em suas conclusões sobre os textos estudados. Então não faz diferença mudar os pressupostos se as conclusões são as mesmas? A questão é que as conclusões podem ser semelhantes, mas ao levar em conta pressupostos distintos, os desdobramentos das reflexões ganharão outras proporções.

A similaridade nas conclusões sobre os objetivos dos textos, ao mesmo tempo em que se percebe certa proximidade no conceito do Sitz im Leben dos textos, mostra que se pode pensar de forma mais fluida a elaboração dos textos dentro de sua forma (cf. a Crítica das Formas), ao mesmo tempo em que se estuda o objetivo de cada evangelho na forma de registrar a memória (segundo a CR). Isso conecta a Crítica da Redação com a Crítica das Formas, deixando de ser dois olhares estanques sobre o mesmo texto, mas percebendo que o fluxo da oralidade se converteu em texto escrito sem perder a dinâmica que proporcionou sua transmissão. Nesse ponto, a perspectiva da memória social auxilia numa nova interpretação da redação do texto, tirando-o do mundo de um autor isolado e personalista e colocando-o na dimensão de uma comunidade cuja busca de identidade e personalidade gera textos que expressam seu pensamento.

Com relação aos desdobramentos e implicações, podemos deixar aqui algumas questões que podem ser mais bem analisadas em futuras reflexões: para começo de conversa, como articular essa proposta com a ideia de que os evangelhos respondem a determinados contextos? Afinal, se o Sitz im Leben responde a uma dinâmica da vida, que naquele mundo era melhor expresso na oralidade, que motivos eles tiveram para produzir o texto e, de certo modo, cristalizar a tradição, ao menos para aquela comunidade?

Outra questão que se levanta é: como pensar a Fonte Q? Deve-se descartar completamente toda a pesquisa da Fonte Q como uma produção literária própria, considerando-a apenas um conjunto de materiais orais que foram recebidos pelas comunidades de Mateus e Lucas sem que houvesse qualquer material escrito? Nesse caso, por que Marcos ignora completamente esse material?

Por fim, podemos colocar outro ponto em aberto: como explicar os materiais exclusivos nessa perspectiva? Seriam bancos de memória próprios, vindos da tradição de Jesus, mas ignorados pelas demais comunidades, ou textos produzidos a partir da reflexão da própria comunidade, tendo como base os materiais anteriores? Em especial podemos pensar nos materiais de Marcos que nem Mateus nem Lucas aproveitaram: por que não o fizeram? Eles os ignoraram deliberadamente, ou esses materiais não se justificavam em suas propostas de elaboração do registro das atividades de Jesus?

Em suma, ficam várias questões, que demonstram que a Crítica da Redação, como um dos braços dos métodos histórico-críticos, não se esgotou, pois ainda pode gerar diversos debates e perspectivas de leitura dos textos evangélicos e de outros escritos do Novo Testamento.

\section{Referências}

BYRSKOG, Samuel. A New Quest for the Sitz im Leben: Social Memory, the Jesus Tradition and the Gospel of Matthew. New Testament Studies, n. 52, p. 319-336, 2006. 
CARNEIRO, Marcelo. Os Evangelhos Sinóticos: origens, memória e identidade. São Paulo: Fonte; Terceira Via, 2016.

EGGER, Wilhelm. Metodologia do Novo Testamento. São Paulo: Loyola, 1994.

KIRK, Alan; THATCHER, Tom (Ed.). Memory, Tradition, and Text. Use of the Past in Early Christianity. Atlanta: Society of Biblical Literature, 2005.

KOESTER, Helmut. Introdução ao Novo Testamento 2. História e Literatura do Cristianismo Primitivo. São Paulo: Paulus, 2005.

KÜMMEL, Werner G. Introdução ao Novo Testamento. 2. ed. São Paulo: Paulus, 1982.

MARCONCINI, Benito. Os evangelhos sinóticos: formação, redação, teologia. São Paulo: Paulinas, 2001.

MYERS, Ched. O Evangelho de São Marcos. São Paulo: Paulinas, 1992.

NOVO TESTAMENTO Interlinear Grego-Português. Trad. Vilson Scholz e Roberto G. Bratcher. Barueri: Sociedade Bíblica do Brasil, 2004.

OPORTO, Santiago Guijarro. Ditos Primitivos de Jesus. Uma introdução ao "Proto-evangelho de ditos Q”. São Paulo: Loyola, 2006.

ORCHARD, Bernard; LONGSTAFF, Thomas R. W. (Ed.). J. J. Griesbach: Synoptic and textcritical studies. 1776-1976. Cambridge: Cambridge University Press, 1978.

ROBERTS, Alexander; DONALDSON, James (Ed.). Ante-Nicene Fathers. Buffalo: Public Domain, 1885. v. 1.

SCHNELLE, Udo. Introdução à Exegese do Novo Testamento. São Paulo: Loyola, 2004.

STEIN, Robert H. What is Redaktionsgeschichte? Journal of Biblical Literature, v. 88, n. 1, p. 45-56, March 1969.

STROUMSA, Guy G. Religious Memory, between orality and writing. Memory Studies, v. 9, n. 3, p. 332-340, 2016.

WEGNER, Uwe. Exegese do Novo Testamento: manual de metodologia. 7. ed. São Leopoldo: EST; Sinodal, 2012. 